Daimon. Revista Internacional de Filosofía, Suplemento 5 (2016), 155-162

ISSN: 1130-0507 (papel) y 1989-4651 (electrónico)

http://dx.doi.org/10.6018/daimon/269991

\title{
Notas sobre la antropología de Kierkegaard
}

\author{
Notes on the Anthropology of Kierkegaard
}

\begin{abstract}
Resumen: El presente artículo pretende arrojar algo de luz sobre la comprensión kierkegaardiana del ser humano. La recepción del pensador danés ha subrayado a veces en exceso su carácter fideísta e irracionalista. En este artículo se intenta mostrar que Kierkegaard no piensa al ser humano desde esas coordenadas. La manera de abordar la desesperación, la infancia y el ser espíritu impedirían encuadrar su aporte filósofico en ellas. Su crítica de la razón así como la relevancia que le da a los acontecimientos y a la alteridad nos ayudan a acercarnos sucintamente al misterio que somos cada uno de nosotros.
\end{abstract}

Palabras clave: Kierkegaard, acontecimiento, espíritu, desesperación, infancia, irracionalismo.

\author{
ÁNGEL VIÑAS VERA*
}

\begin{abstract}
This article aims to shed some light on Kierkegaard's understanding of the human being. Commentators have at times excessively stressed the fideist and irrationalist character of his works. This article attempts to show that Kierkegaard does not approach the human being from those coordinates. The way he deals with despair, childhood and being spirit prevents us from framing his philosophical contribution according to those two axes. His critique of reason as well as the relevance he grants to events and alterity help us to subtly draw near the mistery that each of us is.
\end{abstract}

Keywords: Kierkegaard, event, mind, despair, childhood, irrationalism.

La lectura de Kierkegaard ha estado a veces marcada por destacar su fideísmo, su cristianismo y su irracionalismo. A veces se ha utilizado esos calificativos para colocar al pensador danés en un lugar solitario. El deseo de querer subrayar su peculiaridad e, incluso, su difícil clasificación dentro del espectro filosófico ha conllevado, por el contrario, el situarlo como al margen de todo diálogo fecundo. Las corrientes fideístas, cristianas e irracionalistas son muchas y variadas. En ellas podemos seguir bebiendo y aprendiendo. Pero creo que el autor danés debe ser revisado desde otras categorías. El presente artículo quiere poner sobre la mesa tres notas sobre la antropología del autor danés que hagan repensar la comprensión que de este autor tenemos. Asimismo la encuadramos en las temáticas del VII Congreso de la Sociedad Académica de Filosofía 2015, "Filosofía y cuerpo desde el pensamiento grecoromano hasta la actualidad." En memoria de Rocío Orsi Portalo.

Fecha de recepción: 11/06/2016. Fecha de aceptación: 20/07/2016.

* Doctorando en la Universidad Pontificia Comillas. angelsscc@gmail.com. Las líneas de investigación son la filosofía de la religión y la ética. Algunas publicaciones recientes: "Sufrimiento y justicia. Dialogando con Adela Cortina" en Olga Belmonte (Coord.), De la indignación a la regeneración democrática, Universidad Pontificia Comillas, 2014. "Sobre la verdad, el existir y el morir: Søren Kierkegaard” en Razón y fe, 2013, pp. 473-482. 
Las notas que aquí se van a desarrollar son: una anotación sobre el cuerpo y la desesperación, otra sobre el irracionalismo de Kierkegaard y por lo último en qué consiste que el existente, el individuo, sea fundamentalmente espíritu y que, en ello, consiste su gloria. El objeto de este escrito es por medio de estas notas, incompletas, ayudar a repensar el planteamiento de Kierkegaard sobre el ser humano. En concreto, me gustaría mostrar la relevancia que él le da al ser humano como espíritu, es decir, libertad radical y enmarañada desde el principio y de ahí la imposibilidad de entender al ser humano sólo desde el cuerpo o desde el alma. Desde aquí podría iluminarse el lugar tan relevante que tiene la razón así como sus límites en el querer pensar el existente, dios, el tiempo, el amor. Asimismo podremos acercarnos brevemente a cómo la naturaleza tan singular del ser humano entendida como espíritu es una defensa radical de la libertad del ser humano, una libertad enfrentada desde su origen al misterio del Bien y del Mal. Una libertad que no se tiene por qué enredar en los lazos infinitos de comprensiones y horizontes de comprensión porque tiene una tarea absoluta, decisiva, definitiva: la de llegar a ser feliz, pleno, dichoso, libre.

\section{I.}

Adentrémonos en estas notas sobre algunos aspectos de la visión del existente que el pensador danés nos ha dejado en su obra entregada y publicada en vida. En esta primera nota nos acercaremos al diablo. En él podremos ver la peculiaridad de la desesperación en relación al ser espíritu del ser humano y la relevancia que tiene el cuerpo en nuestro vivir.

Nos dice Kierkegaard:

La desesperación del diablo es la más intensa de todas, ya que el diablo es puro espíritu y por ello conciencia y transparencia absolutas; en el diablo no se da ninguna oscuridad que pueda servir de atenuante y por eso su desesperación es la más absoluta de todas. Éste es el grado máximo de desesperación ${ }^{1}$.

El ser humano es un intento de síntesis de cuerpo y alma, tiempo y eternidad, necesidad y libertad, finitud e infinitud, etc. Cuando Kierkegaard afirma esto no está queriendo implicarse en una visión dualista clásica ya que supondría hacer un discurso onto-teológico ajeno a su manera de acercarse al ser humano. En su mirada fenomenológica y existencial, el ser humano no tiene necesariamente que vivirse como uno y único. Todos los pseudónimos nos muestran que ser hombre se puede decir de muchas maneras y que muchas veces la misma persona se vive desdoblada, desencajada, quebrada, dividida... Como si no viviéramos sólo una vida. Como si el ser humano pudiera pasar por momentos en la vida tan peculiares que le hicieran pensar que ha nacido de nuevo, que ha muerto a ciertas vidas.

El ser humano puede a veces vivirse como si fuera él mismo una legión de personas o personajes. Es por ello que la unidad del ser humano, el vivirse como uno, unificado, es una tarea casi infinita. El vivirse como síntesis de lo anteriormente apuntado desde su ser espíritu es algo que ni se dio en el nacimiento. Como se nos indica en la manera en que el

1 Anti-Climacus, La enfermedad mortal o de la desesperación y el pecado. Una exposición cristiano-psicológica para edificar y despertar. Editorial Trotta, 2008, p. 64. 
espíritu está en el niño en El concepto de angustia, pasando por el esteta de los papeles de A en $O$ lo uno o lo otro hasta llegar a los cristianos de su época que tienen el corazón dividido entre Cristo y el estado. El espíritu en la infancia, en la inocencia primera está soñando. Está dormido de ahí que la nada pueda presentar esa fuerza tan extraña y tan ambigua.

Considero pues, analizando el texto citado, necesario reivindicar la importancia que tiene la vivencia del cuerpo en el ser humano como aquel que, junto con el mundo, forman parte de esa oscuridad que impide al ser humano desesperar del todo. El cuerpo se nos ha dado de tal manera que nos impide tener una desesperación absoluta. Eso pone de manifiesto una ambigüedad radical en la vivencia del cuerpo: dado que no nos deja tener una transparencia absoluta nos posibilita no desesperar del todo así como, por otra parte, muestra la dificultad que la vivencia del cuerpo supone para aquel que quiere vivirse como espíritu. El ser humano no es sólo espíritu pero tampoco es sólo cuerpo o alma. El ser humano va a querer vivirse a veces como cuerpo solo o como alma solo. La síntesis nunca está del todo terminada. El tiempo puede ser un aliado o una carga para el existente.

La imposibilidad de tomar la descripción kierkegaardiana desde los parámetros clásicos de cuerpo y alma se evidencian aquí más aún si cabe. El hombre podría vivir, según esta manera de describir las maneras que tenemos de vivirnos, como cuerpo solo y como alma solo. En ningún caso parece que el existente se vive como lo que podría y debería ser. La síntesis, la tarea misma de la vida que consiste en enfrentarse día a día con el bien que no he hecho y el mal en el que he incurrido, es otro nombre de la libertad. La tarea inmensa es no renunciar a ser ese existente que se vive corpóreo y anímico. Vivirte sólo como cuerpo o vivirnos sólo como alma nos lleva a no vivir como hombres y desesperar por no ser lo que somos. Ya sabemos que la desesperación mayor es aquella que ni sabe que está desesperado. La enorme dificultad para hacer despertar al hombre de esa situación no podrá hacerse sólo con una toma de conciencia solipsista. Los acontecimientos y los otros jugarán un papel decisivo para saber quién soy y cómo estoy siendo hombre. El problema no es fundamentalmente olvidar el cuerpo o sobrevalorar el alma. El problema es olvidar que el existente, el que quiera vivirse como tal, como individuo, no se vive sólo como uno o como otro. Lo que está en juego no es el dualismo sino el vivirnos como seres humanos, es decir, no desesperar olvidando lo que somos aún sin darnos cuenta.

\section{II.}

Algunas lecturas supusieron en su momento un hito en la recepción kierkegaardiana ${ }^{2}$. Es posible hacer una lectura de la obra de Kierkegaard que quiera mostrar la contundencia de la respuesta a un exceso racionalismo filosófico precedente. Hay motivos más que de sobra. Desde aquí cabe entender, por ejemplo, la enorme reticencia que tiene Kierkegaard a llamar a Dios el Espíritu. Aunque tenga resonancias bíblicas, Kierkegaard preferirá utilizar más el Bien, el Amor, el Uno, o simplemente Dios.

2 Chestov, L. Kierkegaard y la filosofía existencial. Ed. Sudamericana. 1947. Esta obra marcó una lectura de la obra kierkegaardiana. En ella se subrayaba más los elementos fiduciales e irracionalistas. 
Sin dejar de ver el valor que hay en esta tesis que quiere enfatizar el posible irracionalismo de Kierkegaard frente al ambiente de la Europa del siglo XIX, creo que Kierkegaard hace una crítica de la razón en sus obras. Él intenta mostrar las posibilidades y límites de la misma. Para ello piensa la razón que está movida por el interés de encontrar vida y vida buena para él y para su querido lector. No se trata, pues, de lanzar fuera la razón del ámbito de la filosofía o del existente o de la vida. De lo que se trata es de ver cómo es el uso más adecuado de ella para poder pensar el individuo, la alegría, el presente, la culpa, etc.

Entiendo que las posibilidades de la razón marcadas por Kierkegaard están limitadas no por el poco alcance de la misma, sino por algo más radical aún: la razón quiere pensar lo impensable, lo que no se deja apresar, lo misterioso, lo desconocido. La pregunta de Kierkegaard apunta más a por qué el ser humano se plantea todo eso así como qué es lo que le lleva a plantearlo. El origen de estas preguntas o de estos deseos no es la mera constatación del enigma o misterio que se le impone sino el deseo de vida plena, de verdad absoluta. Porque el hombre aspira a la verdad absoluta es por lo que la razón se queda corta. La razón es movida y llevada y animada por una pasión. He aquí donde se sitúa la paradoja y los límites de la razón. Por un lado nos encontramos con la pasión que arranca de la vida y que quiere plenitud y salir de la duda, y por otro lado la razón que choca contra lo desconocido. El existente, que no puede ser reducido a ser cognoscente, debe ir haciendo camino en este vivirse donde los acontecimientos le ayudarán a depurar más y más la razón así como aquello a lo que llama verdad y bien. Es por ello que cabría decir que Kierkegaard es un auténtico racionalista, es decir, aquel que usa la razón para acometer la empresa radical que tiene la razón de un existente: pensar su vida para que sea mejor, dichosa, plena.

El irracionalismo de Kierkegaard sería posible mantenerlo pero creo que no se ajustaría ni a lo que él hizo ni cómo lo hizo en sus obras. Su crítica de la razón quiere mostrar la alegría perfecta que el pensador danés buscaba, el bien perfecto que el existente busca. Este no puede ser sólo indagado con la razón. Es al existente a quien le preocupa, y mucho todo eso. No se trata de hacer un nuevo pensamiento o un nuevo edificio donde no se pueda vivir. No se trata de montar otro sistema donde la vida de quien lo crea sea un parágrafo del mismo. Se trata de buscar una verdad que sea verdadera para mí, que me haga verdadero.

Es por ello que la crítica de la razón de Kierkegaard remite a algo más radical aún: la teoría de la acción, de la apropiación, de la verdad del existente y para el existente. Se hace necesario e imperioso que, para poder pensar bien y con radicalidad la verdad, el existente entre a esa aventura de vivir con una actitud radical. Esta actitud que Sócrates consideraba esencial y que consistía en no considerar la muerte como el peor de los males y el miedo como fuente de comportamiento. Es la actitud radical a la que apuntaba Husserl ${ }^{3}$ de poner en cuestión radicalmente las fuentes de donde emanan el brillo o el valor de nuestras verdades. Es la actitud radical, como indicará Kierkegaard, de quien cuando empieza a pensar y a buscar la verdad descubre, no sin dolor, que es culpable y que sufre. ¿Cómo podrá encon-

3 "Pero cuando nos volvemos hacia esta gran meta interpretando el sentido de nuestra época, tenemos que tener muy claro que sólo podemos alcanzarla de una manera: si con el radicalismo propio de la esencia de la ciencia filosófica auténtica, no aceptamos nada previamente ya dado; si no dejamos vigente, para empezar, nada tradicional ni dejamos que nos ciegue ningún nombre, por grande que sea, sino, antes bien, intentamos ganar los comienzos entregándonos con libertad a los problemas mismos y a lo que ellos exigen." E. Husserl, La filosofia, ciencia rigurosa. Ediciones Encuentro, Opuscula Philosophica 39, 2009, p. 84. 
trar la verdad absoluta el que no es bueno? ¿Es ajeno a aquella pregunta esta constatación dolorosa? ¿No se hace necesario para aquello un pararse y mirar detenidamente el camino y el modo de vivirse para poder ver si acertaríamos en aquella magna empresa? ¿Es posible descubrir todo con la razón sin necesidad de acoger las enseñanzas que el actuar propio y ajeno nos da? ¿Es que el actuar humano no enseña, no nos enseña? ¿Cómo debe acoger la razón humana las enseñanzas que recibimos una vez que actuamos? A lo mejor debemos reconocer con $\mathrm{M}$. Blondel, y otros autores, que hay un hiato entre el pensar y el querer, y otro más profundo entre el querer y el actuar. Que no sólo basta con pensar con claridad y rigurosidad. Que no es suficiente tener una intención y una voluntad tan santa como la que describía Kant sino que se hace necesario acoger las enseñanzas que recibimos una vez que actuamos, que amamos, que perdonamos, que nos perdonan, que prometemos, etc.

Es desde este hiato desde donde podemos repensar la intersubjetividad, la corporalidad y otros elementos configuradores del existente. El solipsismo kierkegaardiano no es asumible. La lectura de su obra completa, no sólo ciertos pseudónimos sino toda su obra entregada al mundo con sus dos manos, impiden una lectura donde el individuo va sacando de su interior todas las verdades necesarias para vivir.

III.

A Kierkegaard le preocupaba, y mucho, la situación de su época. Las convulsiones en su país y en Europa son notorias y conocidas por él. La preocupación por el hombre se refleja en sus escritos. El deseo de pensar lo que veía y escuchaba en sus paseos, lo que escuchaba en el teatro y de lo que se hablaba en la plaza le impulsaba a seguir pensado, a ir más adentro. La letanía en todos sus escritos a mi querido lector no es sólo una cortesía. Es que es a su querido lector para el que desea que sus escritos pudieran llegar a ser ocasión para que éste descubra vida. Kierkegaard no es ningún maestro. Pero leerle a él en voz alta puede ayudarnos a preguntarnos sobre aquello que somos.

El hombre es espíritu. Más ¿qué es el espíritu? El espíritu es el yo. Pero ¿qué es el yo? El yo es una relación que se relaciona consigo misma, o dicho de otra manera: es lo que en la relación hace que ésta se relacione consigo misma. ${ }^{4}$

Ser espíritu es la gloria del ser humano, nos indica en varios momentos de sus discursos. Como hemos indicado en la primera nota de este escrito, el ser humano vive de diversas y múltiples manera su corporalidad, su ser anímico y su ser espíritu. Kierkegaard así nos lo muestra. Desde el Don Juan, el seductor, el magistrado Wilhem, los pseudónimos, Abraham, Job, el pagano, Sócrates, el contemporáneo de Cristo, el individuo, etc. van mostrando su manera de vivirse. Toca aquí mostrar algo de en qué consiste esta singularidad del ser espíritu. Sólo me referiré a lo que considero más pertinente en orden al objeto indicado al principio de esta escrito. El tema del ser espíritu en nuestro autor exige un análisis mucho más detallado del que aquí pobremente se enuncia.

4 Anti-Climacus, La enfermedad mortal o de la desesperación y el pecado. Una exposición cristiano-psicológica para edificar y despertar. Editorial Trotta, 2008, p. 33. 
Nos dice Kierkegaard:

La inocencia es ignorancia. En la inocencia no está el hombre determinado como espíritu, sino sólo anímicamente determinado en unidad inmediata con su naturalidad. El espíritu está entonces en el hombre como soñando. ${ }^{5}$

Kierkegaard dedicó al menos en dos momentos el problema de la entrada en la existencia y la naturaleza tan singular de la existencia humana. En el Concepto de angustia ${ }^{6}$ así como en La enfermedad mortal ${ }^{7}$ aborda con su estilo característico y, dentro de dos obras con finalidades y estilos diferentes, la identidad del yo, el ser humano como espíritu. Lo primero que llama la atención sobre esta entrada en la existencia es que no puede vivirse sin vivirse a la vez un cierto hiato, salto o interrupción, o convulsión.

La insistencia de Kierkegaard de afirmar que hay realidades humanas que no comienzan más que con un salto (el pecado entra en el mundo por un pecado, la libertad por un acto libre, culpa, el estadio ético, etc.) pone de manifiesto a mi entender la enorme importancia que da nuestro autor a la libertad y a los acontecimientos. No se trata de desarrollar las potencialidades que el ser humano tiene por naturaleza simplemente o un nuevo pensamiento que el ser humano elabora a partir de todo lo vivido y pensado. Se trata de una situación nueva donde el ser humano siendo él mismo no se viva de la misma manera ni ya sea el mismo. Se trata de un salto de libertad que es a su vez un ser parido y removido. Es un movimiento pasivo y activo a la vez. No se hace sin el individuo, de ahí la culpabilidad con la que se nace a la existencia, pero no es sólo un acto de voluntarismo propio. El ansia que anida en el niño, de la que nos habla Kierkegaard, apunta a esta ambigüedad radical.

La entrada en la existencia aparece como un despertar de un sueño. El espíritu parece estar soñando y los acontecimientos le hacen despertar. Cuando despierta y toma conciencia de sí eligiéndose, se da cuenta que ya su libertad está enmarañada y culpable de no vivirse y elegirse adecuadamente. $Y$ esto no debe ser necesariamente así sino que en cada persona está en juego porque cada uno es él mismo y la especie.

Kierkegaard nos habla de la figura del niño para poder entender algo mejor cómo está el espíritu anteriormente. El espíritu está como jugando, sin tomar conciencia de lo que es él mismo, jugando a ser diversas personas o vidas. Esta ansia, que no angustia, supone un movimiento, interés, vida ante la posibilidad que le aparece en la libertad. Serán los acontecimientos lo que hagan de cimbreadores y posibilitadores para que el espíritu tome conciencia de lo que es. Pero he aquí algo singular. El espíritu no es una autoconciencia de sí. No es sólo eso aunque también lo sea. Kierkegaard nos ha dicho, como hemos citado ya, que es una relación que se relaciona consigo misma. El yo no es autoconciencia sólo sino una relación que se hace a partir o con esa autoconciencia. Por eso nos añade en estos textos que cuando el espíritu despierta y siente el vértigo de la libertad hace un movimiento tal que se siente culpable en el momento siguiente. En El concepto de angustia lo que se

5 Kierkegaard, S. El concepto de angustia. Un mero análisis psicológico en la dirección del problema dogmático del pecado original. Alianza Editorial, primera edición de 2007 (segunda impresión de 2010), p. 87.

6 En especial el primer capítulo del citado libro: "La angustia como supuesto del pecado original y como medio de su esclarecimiento, precisamente re-procediendo en la dirección de su origen."

7 En especial del libro primero, la primera parte "Que la desesperación es la enfermedad mortal". 
nos muestra es la singularidad de la libertad humana. No se trata de mostrar un ansia por no ser sólo el que soy o vivir de manera oculta o dormida el espíritu. Se trata de eso y de algo más. Se trata de despertar y elegirme a mí mismo, son dos movimientos o dos aspectos en el mismo. Es por eso que desde el principio la libertad y todo lo que ella supone, emergen en el nacimiento y en la entrada en la existencia.

El espíritu apunta en Kierkegaard a, como hemos dicho, una filosofía de la libertad. El espíritu es una manera de vivirse y de caminar. El espíritu despierto es el que está absolutamente interesado por su vida, por su vivir y el que no puede descansar hasta que encuentre una verdad que sea verdad para él, es decir, que le de vida buena. El espíritu busca el bien desde las cenizas de su culpabilidad. El espíritu humano es superior al de las aves y los lirios, y de la naturaleza entera. Puede más y menos. No está ajustado ni determinado a ser una cosa o la otra. Puede aprender de estos o no. Puede vivirse mejor que un ave pero puede vivirse también peor que un animal. El espíritu no nace hecho desde el nacimiento, no nace con un conocimiento natural o sobrenatural de lo que es él o el bien o el mal. La libertad, el tiempo, los acontecimientos son decisivos y son los mejores regalos que el dios ha hecho al hombre.

Es por ello que la filosofía de Kierkegaard no entra por los caminos de una teología natural que se entienda al margen de las enseñanzas que da el vivir así como tampoco un discurso de la naturaleza humana universal que incluya como punto de partida un deseo de bien que es sin más deseo de Dios. No parece que el hombre nazca ya terminado.

Pero Dios es espíritu, es invisible, y la imagen de lo invisible también es invisible. De este modo, el creador invisible se rebota a sí mismo en la invisibilidad, que es la determinación del espíritu, y la imagen de Dios es precisamente la gloria invisible. Si Dios fuese visible, indudablemente que nadie podría asemejarse a Él o ser su imagen, pues no existe imagen de todo lo visible, y entre todo esto no hay nada, ni siquiera una hoja, que se asemeje a otra o sea su imagen. ${ }^{8}$

No parece que se deba interpretar necesariamente el que sea imago dei como si ya conociera de forma innata o tuviera un deseo innato de Dios. Como tampoco sabe desde el principio que se muere. La nada del ansia no remite a nada en concreto ni supone una facticidad irrevocable del existente. Igual su ser espíritu, que es su gloria, nos pone en la pista de un ser tan peculiar que su nacer no puede ocurrir sin la intervención del mismo que nace. Como si el espíritu no pudiera ser tal sin el actuar del mismo espíritu. Y eso lo hace todo enormemente problemático. El ansia del hombre en sus momentos iniciales del existir es un ansia indeterminada de bien y mal. Sin los acontecimientos que le van ocurriendo no podrá purificar y modificar ese deseo de tal manera que pueda descubrir qué es lo que desea y cómo.

A modo de conclusión podríamos recapitular diciendo que el ser humano no es sólo espíritu ya que tenemos cuerpo y mundo-tiempo. Su ser espíritu no es algo que se refiera a algo que tiene sino a algo que es. Y es una tarea siempre inacabada. Es una síntesis que es

8 Kierkegaard, S. Los lirios del campo y las aves del cielo., Editorial Trotta, p. 60. Estos discursos edificantes dedicados a este texto evangélico tan querido son un desarrollo, entre otras cosas, de lo que el hombre puede aprender y no sabía de lo que la naturaleza ya vive y él puede o no aprender. 
una tarea, la tarea incesante de ser bueno, de no desesperar ni de hacer desesperar, la tarea de más verdad. Un espíritu que no quiere olvidar toda su existencia a la hora de pensar el mundo, Dios y a él mismo. Un existente que quiere llevar a la razón a pensar la dicha plena escondida en el sufrimiento.

\section{Bibliografía}

Chestov, L. (1947): Kierkegaard y la filosofía existencial, Ed. Sudamericana.

Husserl, E. (2009): La filosofía, ciencia rigurosa, Ediciones Encuentro, Opuscula Philosophica 39, Madrid.

Kierkegaard, Søren (2007): El concepto de angustia. Un mero análisis psicológico en la dirección del problema dogmático del pecado original, Alianza Editorial, Madrid.

Kierkegaard, Søren (2007): Los lirios del campo y las aves del cielo, Editorial Trotta, Madrid.

Kierkegaard, Søren (2008): La enfermedad mortal o de la desesperación y el pecado. Una exposición cristiano-psicológica para edificar y despertar, Editorial Trotta, Madrid. 